\title{
Validation Study of Active Microwave Soil Moisture Products in Korea and Brazil
}

\author{
Eunsang Cho, Gabriel Alves Vasconcelos, and Minha Choi
}

\begin{abstract}
Soil moisture is a key component of the hydrology meteorology, climatology, and agriculture management in terms of interaction between land surface and atmosphere. Understanding energy and water cycles processes is needed to accurately monitor spatial and temporal variability of soil moisture. In this study, we conducted validation study of active microwave satellite soil moisture data by comparing and evaluating with in-situ soil moisture measured from South Korea and Brazil. The satellite data are derived from the advanced Scatterometer (ASCAT) on board the Metop (VV polarization C-band to $5.255 \mathrm{GHz}$ ) satellite, called as Soil Water Index (SWI). We will focus on growing season from May through September in 2012, to avoid any effect on soil moisture data quality due to the severe wintry weather. The comparison results of this validation task were expressed in three statistical values: Correlation coefficient (R), Bias and Root Mean Square Error (RMSE). The results showed that the ASCAT SWI products have reliable agreements with ground measurements in Korea and Brazil.
\end{abstract}

Index Terms-ASCAT, remotely sensed soil moisture, in situ soil moisture, soil water index.

\section{INTRODUCTION}

One of the main keys of interaction between hydrosphere, biosphere and atmosphere is soil moisture, which in any type of soil and climate has important factor in the water cycle. Therefore, soil moisture monitoring with the required spatial (100-1000 $\mathrm{km}^{2}$ ) and temporal (nearly daily) resolution can greatly enhance flood prediction and forecasting [1]. However, even with many methods developed for monitoring the moisture in-situ soil, such as gravimetric, neutron scattering, electrical resistance and time domain reflectometry (TDR), is not feasible over large areas, such as the Brazil, because these methods are time consuming and labor. Hence, a number of studies have been conducted or are currently underway to obtain soil moisture estimates from spaceborne microwave instruments [2]-[6]. Firmly, microwave remote sensing is able to provide quantitative information about surface soil moisture, particularly in the low-frequency microwave region from 1 to $10 \mathrm{GHz}$ [7].

Manuscript received April 5, 2014; revised July 5, 2014.

Eunsang Cho is with Department of Civil and Environmental Engineering, Hanyang University, Seoul 133-791, Republic of Korea (e-mail: eunsangcho@hanyang.ac.kr).

Gabriel Alves Vasconcelos is with the Department of Civil Engineering, University of Brasília, Distrito Federal, Brazil (e-mail: gabriel-alves@hotmail.com).

Minha Choi is with Water Resources and Remote Sensing Laboratory, School of Civil, Architectural, and Environmental Engineering, Sungkyunkwan University, Suwon 440-746, Republic of Korea (e-mail: mhchoi@skku.edu)
Thus, the lack of data on soil moisture for the Brazilian territory, with the level of accuracy and the geographic extent necessary for studies on a regional scale, limited understanding of the interaction between soil moisture and the atmosphere. On the other hand, even South Korea is a country of smaller dimensions they have a range of 50 sampling stations of in-situ measurements. Therefore, it is possible to do the validation of remote sensing data with an unquestionable quality, even if this study we will only be 5 stations with the highest values of correlation coefficient.

In this paper, the main purpose is to assess the accuracy of soil moisture estimates from the ASCAT sensor comparing them with in-situ data for two different regions. Therefore, a recursive exponential filter formulation which allows to estimate the SWI (Soil Water Index) from intermittent SSM measurements [8] is used to compare the quality of the data between Brazil and South Korea.

\section{Study AREA AND IN-Situ MEASUREMENT}

\section{A. South Korea}

Korean peninsula, located in northeast Asia, has range 33-39 $\mathrm{N}$ in latitude and 124-131E in longitude. The Korean peninsula has a temperate humid climate. Annual precipitation ranges from 900 to $1600 \mathrm{~mm}$. More than half of the total rainfall amount is concentrated in June and July, while precipitation of winter is less than $10 \%$ of the total precipitation. In other words, precipitation in Korea has large spatio-temporal variability due to the Asian monsoon season [9]. We used data sets from the Rural Development Administration (RDA, http://rda.go.kr) in Korea. The ground based soil moisture measurements were obtained at a depth of $10 \mathrm{~cm}$ on an hourly basis at five locations from May 1 to September 30 in 2011.

\section{B. Brazil}

We use only the values of soil moisture retrieved from the experimental site "Pé de Gigante", located in Santa Rita do Passa Quatro, State of Sao Paulo. Whose geographical coordinates are $\left(21^{\circ} 36^{\prime} 44^{\prime \prime} \mathrm{S}\right.$ and $\left.47^{\circ} 34^{\prime} 41^{\prime \prime} \mathrm{W}\right)$ and the annual precipitation ranges from 100 to $800 \mathrm{~mm}$. However, in contrast to Korea, Brazil has the main period of precipitation between December and February. A micrometeorological tower is installed in the area administered by the Forestry Institute, which is considered an Area of Ecological Interest.

The predominant soil type is eutrophic Quartz Sand and vegetation is cerrado (corresponding to $79 \%$ of the area). The climate is humid in summer and mild and dry in winter [10]. According to the data available from the meteorological 
station of the Department of Water and Energy of the State of São Paulo (DAEE / SP), is predominant in the dry season months from May to September, has low rainfall [11]. Besides, the meteorological tower of $21 \mathrm{~m}$ height was installed in the northwest sector of the municipality of Santa Rita do Passa Quatro in October 2000. A frequency-domain reflectometer - (FDR) CS615 was used to obtain the information of soil moisture at depths of $0.1,0.2,0.5,0,8$, $1.0,1.5,2.0$ and $2.5 \mathrm{~m}$ [12]. This data was collected from May to September 2012 (personal communication with researcher Dr. Humberto Rocha / University of São Paulo USP).

\section{Remotely Sensed Soil Moisture}

The ASCAT has a good radiometric accuracy and stability with measuring radar backscatter, as same ERS-1 and ERS-2 scatterometers, in a real aperture radar instrument [12]. The Earth is being observed with a spatial resolution of around 50 $\mathrm{km}$ or $30 \mathrm{~km}$ through ASCAT, that uses the VV polarization in the C-band $(5.255 \mathrm{GHz})$. However, even with a great accuracy should be observed closely the land cover and vegetation phenology because the spatial and temporal behavior of the scatterometer is affected by these factors. Then, the methodology in this research is the comparison of the ASCAT soil moisture product and in situ observation. Even the differences depth of the ASCAT product is representative of a layer depth of $0.5-3 \mathrm{~cm}$ and the collected soil moisture in situ of depth around $10 \mathrm{~cm}$.

The exponential filter, as same a semi-empirical approach, is used to convert the surface saturation "ms (t)", into the called Soil Wetness Index "SWI (t)". That filter was proposed by [2] is a simple and effective method to recuperate profile soil moisture values from surface and it depends on the analytical solution of a differential equation.

In the other hand of this simplicity, it was found some algorithm reliable in predicting profile soil moisture values based on surfaces soil moisture data both using in situ observations [9], [13] and model data [14]. For a detailed description of the method the reader may refer to [2], [15]. In this study, the simple recursive formulation of the method is used (Eq. (1) and (2)) [16], [17].

$$
\begin{gathered}
S W I_{n}=S W I_{n-1}+K_{n}\left[\operatorname{SSM}\left(t_{n}\right)-S W I_{n-1}\right] \\
\backslash K_{n}=\frac{K_{n-1}}{K_{n-1}+e^{-\left(\frac{t_{n}-t_{n-1}}{T}\right)}}
\end{gathered}
$$

\section{Methodology}

We obtained the basic statistics index in order to evaluate remotely sensed soil moisture products. A correlation coefficient measures the relationship between two samples. Eq. 3 is formulaic expression of correlation coefficient, where $r_{x y}$ is correlation coefficient of variable $x$ and $y$.

$$
r_{x y}=\frac{\sum_{i=1}^{n}\left(x_{i}-\bar{x}\right)\left(y_{i}-\bar{y}\right)}{\sqrt{\sum_{i=1}^{n}\left(x_{i}-\bar{x}\right)^{2} \sum_{i=1}^{n}\left(y_{i}-\bar{y}\right)^{2}}}
$$
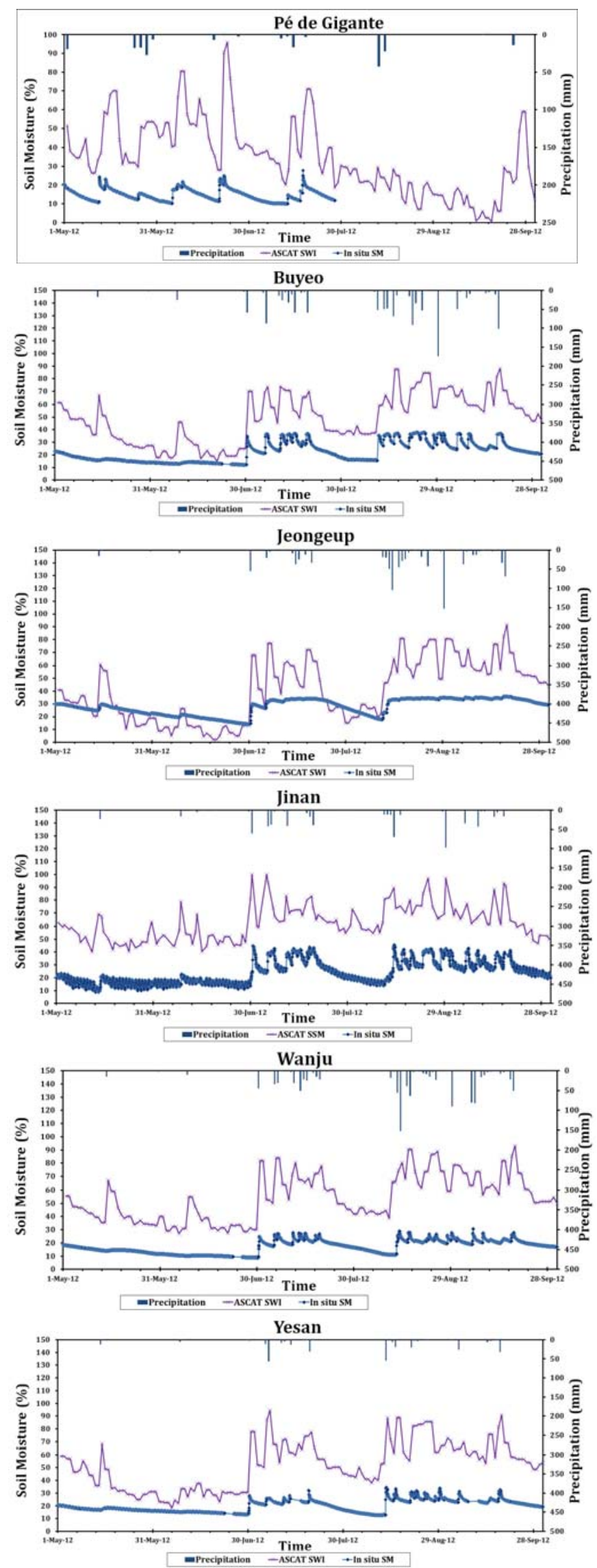

Fig. 1. Times series relative of in situ soil moisture and satellite soil moisture at the five sites in Korea and one site in Brazil.

Bias is the mean value of the differences for each time (Eq. (4)). RMSE is the root mean squared error between the in situ soil moisture measurements and the satellite soil moisture product (Eq. (5)). 


$$
\begin{aligned}
& \text { Bias }=\overline{\sum S M_{\text {satellite }}-S M_{\text {in-situ }}} \\
& R M S E=\sqrt{\sum\left(S M_{\text {satellite }}-S M_{\text {in-situ }}\right)^{2}}
\end{aligned}
$$

\section{RESUlTS AND DISCUSSION}

In the following, the results of the time series comparison between satellite based and in situ soil moisture (SM) in all the chosen locations. Each location was chosen focused on the correlation coefficient. Since, it was pick up the higher values of correlation coefficient between all the sites on the both countries, so it is easy to verify that by the trends between in situ SM and ASCAT SWI curves Fig. 1.
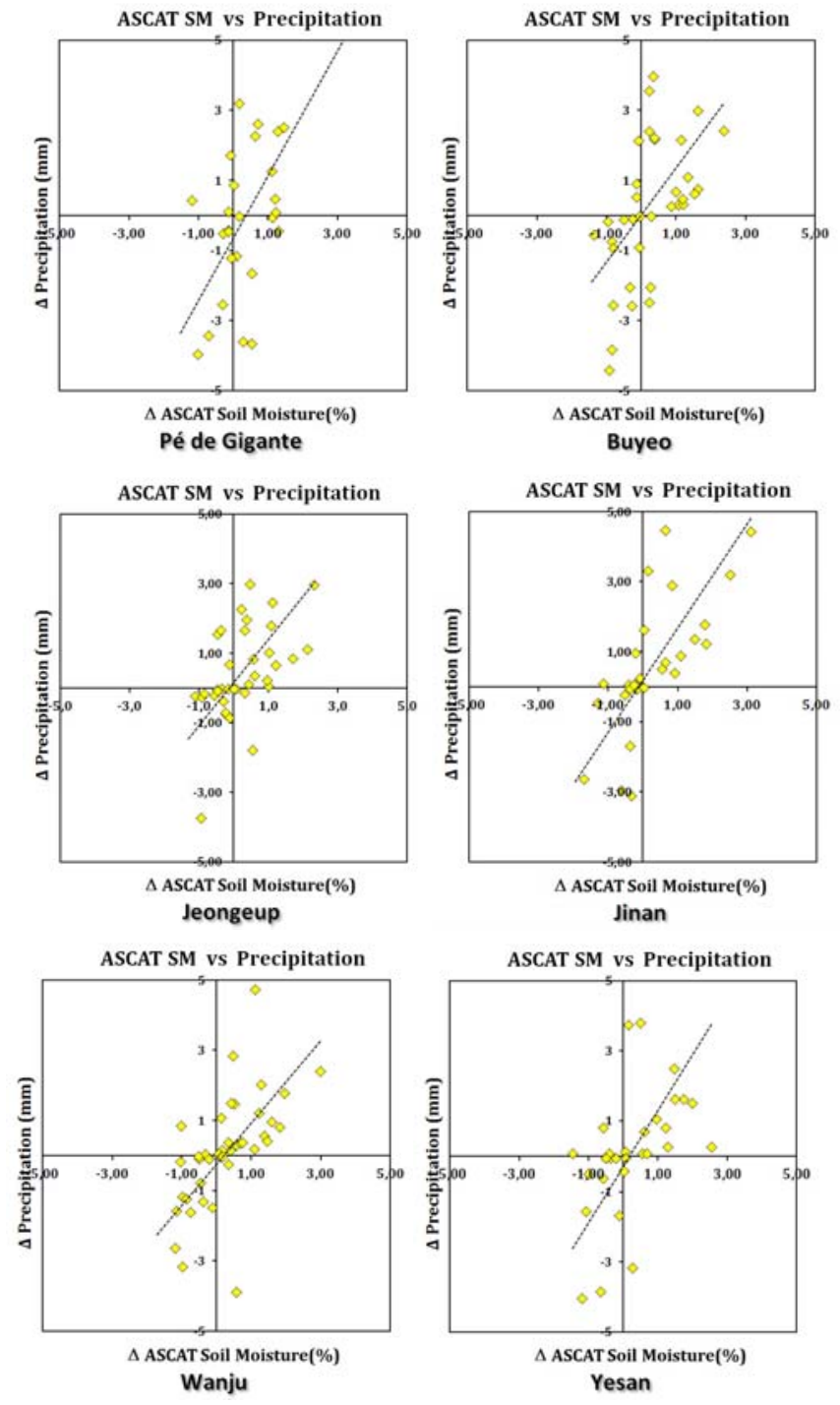

Fig. 2. The gradient of the precipitation change versus the soil moisture change.

Therefore, the analysis on each site above, we can observe a satisfactory relationship between these curves, and also the temporal patterns with the precipitation on the sites in Korea. Thus, it is not only possible to verify that the dry period is related with the lower values of soil moisture, but also the higher values are related with rain period. Besides, we can check this trend by the gradient between the daily differences in ASCAT soil moisture and precipitation (Fig. 2). This figure indicated that the soil moisture increased following precipitation events and then decreased before the next precipitation event. Moreover, it is possible to assess that the
ASCAT SWI values is upper than in situ soil moisture data.

Nevertheless, we can figure out the reasonable trends between the SWI and in-situ SM, even though they have a representative gap between themselves. This relevant relation is verified too by the soil moisture correlation between the data sources. Then, we can observe, by trend of lines from the scatter plots between ASCAT and in-situ soil moisture values, that both Buyeo and Jeongeup sites have the higher correlation values $\left(R^{2}=0.76\right)$ in Fig. 3 .
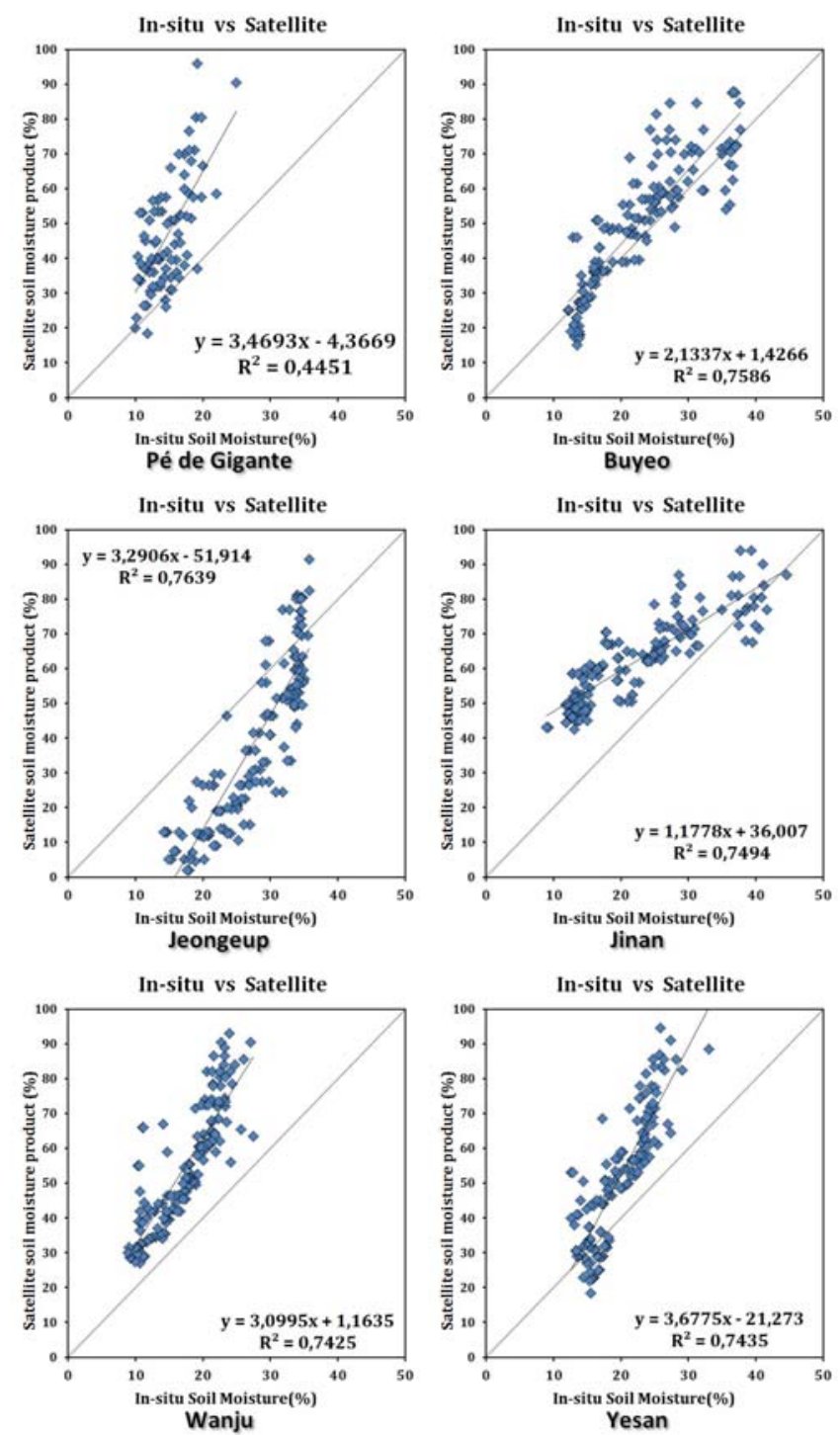

Fig. 3. Scatter plots between in-situ and satellite soil moisture values.

The results of all the comparisons in terms of R-values, Bias, and RMSE are reported in Table I for ASCAT products (SWI, $T=1$ ). Then first, we can compare the numbers of correlation coefficient, so noticed that the Brazilian site has the low value. This R-value could be expected because there is not in situ data after $30^{\text {th }}$ July. In opposite, the higher number of $\mathrm{R}$ coefficient is the Jeongeup site in Korea, that could be observe also by the Fig. 1 .

Furthermore, other analysis that we observed are the high values of BIAS and RMSE, due to the super estimation of SWI to in-situ observations. Therefore, the in-situ soil moisture has a flattened trend. However, in many applications, the general trend of soil moisture values is more representative than their actual values. Concluding, the best indicator to assess the data reliability should be the linear 
correlation coefficient instead of the BIAS and RMSE. Accordingly, in a comparison between Jinan, Wanju and Yesan, it is possible to observe that even Wanju and Yesan have BIAS and RMSE values lower than Jinan, the reliability of the data in Jinan is higher than the others, because of the R-value.

TABLE I: SUMMARY OF THE RESULTS OF THE COMPARISON BETWEEN Site-SPECIFIC AND SATELLITE SOIL MOISTURE FOR THE ASCAT SOIL MOISTURE PRODUCT

\begin{tabular}{llll}
\hline \hline & \multicolumn{3}{c}{ Soil Water Index } \\
\hline \hline Site & $\mathrm{R}$ & BIAS & RMSE \\
\hline Pé de Gigante & 0.67 & -32.00 & 34.94 \\
Buyeo & 0.87 & -27.02 & 29.75 \\
Jeongeup & 0.87 & -12.19 & 22.08 \\
Jinan & 0.87 & -40.00 & 40.51 \\
Wanju & 0.86 & -37.20 & 39.53 \\
Yesan & 0.86 & -31.42 & 34.84 \\
\hline \hline
\end{tabular}

\section{CONCLUSION}

The remotely sensed soil moisture product from the ASCAT was validated using ground-based measurements at five sites in Korea and one site in Brazil. The results show that the ASCAT SWI products have good agreements with ground measurements though systematic errors in Korea and Brazil. As a result, this study might be helpful in the water resource management activities and hydrologic modeling systems.

However, additional data collection efforts, mainly in Brazil, should be conducted. Thus, a wider range of representative validations sites could be created, since the size of this continental country and its various types of vegetation, would improve remotely sensed soil moisture applications for the hydrological sciences.

\section{ACKNOWLEDGMENT}

The authors wish to thank the Rural Development Administration in Korea (http://rda.go.kr) and the Climate and Biosphere Laboratory - IAG/USP in Brazil providing soil moisture. ASCAT level 3 soil moisture data were produced by the Vienna University of Technology (TU-WIEN).

\section{REFERENCES}

[1] J. Komma, G. Blöschl, and C. Reszler. "Soil moisture updating by Ensemble Kalman Filtering in real-time flood forecasting," Journal of Hydrology, vol. 357, pp. 228-242, 2008.

[2] W. Wagner, G. Lemoine, and H. Rott. "A method for estimating soil moisture from ERS scatterometer and soil data," Remote Sens. Environ. vol. 70, pp. 191-207, 1999.

[3] W. Wagner, G. Lemoine, M. Borgeaud, and H. Rott. "A study of vegetation cover effects on ERS scatterometer data," IEEE Trans. Geosci. Remote Sens., vol. 37, no. 2, pp. 938-948, 1999.

[4] W. Wagner, J. Noll, M. Borgeaud, and H. Rott. "Monitoring soil moisture over the Canadian prairies with the ERS scatterometer," IEEE Trans. Geosci. Remote Sens., vol. 37, no. 1, pp. 206-216, 1999.

[5] Y. Kerr, P. Waldteufel, J. P. Wigneron, J. M. Martinuzzi, J. Font, and M. Berger, "Soil Moisture retrieval from space: the Soil Moisture and Ocean Salinity (SMOS) mission,” IEEE Trans. Geosci. Remote Sens., vol. 39, pp. 1729-1736, 2001.
[6] E.-G. Njoku, T. J. Jackson, V. Lakshmi, T. K. Chan, and S. V. Nghiem. "Soil moisture retrieval from AMSR-E," IEEE Trans. Geosci. Remote Sens., vol. 41, no. 2, pp. 215-123, 2003.

[7] T. J. Schmugge. "Remote sensing of soil moisture: Recent advances," IEEE Trans. Geosci. Remote Sens., no. 3, pp. 145-146, 1983.

[8] C. Albergel, C. R. Udiger, T. Pellarin, J. C. Calvet, N. Fritz, F. Froissard, D. Suquia, A. Petitpa, B. Piguet, and E. Martin. "From near-surface to root-zone soil moisture using an exponential filter: an assessment of the method based on in-situ observations and model simulations," Hydrol. Earth Syst. Sci., vol. 12, pp. 1323-1337, 2008.

[9] Korea Meteorological Administration, "Annual Climatological Report," 11-1360000-000016-10, 2006.

[10] L. Rossato, "Estimativa da umidade superficial do solo a partir de sensoriamento remoto por microondas passive sobre a América do Sul," Ph.D. dissertation, Instituto Nacional de Pesquisas Espaciais, São José dos Campos, São Paulo, Brazil, 2010.

[11] R. D. Bruno. "Variabilidade observada da umidade do solo em floresta tropical e cerrado," M.S. thesis. IAG-USP: São Paulo, 2004.

[12] Campbell Scientific, Inc. "Instruction Manual: CS615 Water Content Reflectometers," Campbell Scientific, Inc., Logan, Utah, Revision: 10/96, 1996.

[13] Z. Bartalis, W. Wagner, V. Naeimi, S. Hasenauer, K. Scipal, H. Bonekamp, J. Figa, and C. Anderson. "Initial soil moisture retrievals from the METOP-A advanced Scatterometer (ASCAT)," Geophys. Res. Lett., vol. 34, 2007.

[14] C. Albergel, J. C. Calvet, J. F. Mahfouf, C. Rüdiger, A. L. Barbu, S. Lafont, J. L. Roujean, J. P. Walker, M. Crapeau and J. P. Wigneron. "Monitoring of water and carbon fluxes using a land data assimilation system: A case study for southwestern France," Hydrol. Earth Syst. Sci., 14, 1109-1124, 2010.

[15] B. Bisselink, E. Van Meijgaard, A. J. Dolman, and R. A. M. D. Jeu. "Initializing a regional climate model with satellite-derived soil moisture," Journal of Geophysical Research, vol. 116, 2011.

[16] A. Ceballos, K. Scipal, W. Wagner and J. Martınez-Fernandez. "Validation of ERS scatterometer-derived soil moisture data in the central part of the Duero Basin, Spain," Hydrological Processes, vol. 19, pp. 1549-1566, 2005.

[17] C. Albergel, C. Rüdiger, D. Carrer, J. C. Calvet, N. Fritz, V. Naeimi, Z. Bartalis, and S. Hasenauer. "An evaluation of ASCAT surface soil moisture products with in-situ observations in southwestern France," Hydrol. Earth Syst. Sci., vol. 13, pp. 115-124, 2009.

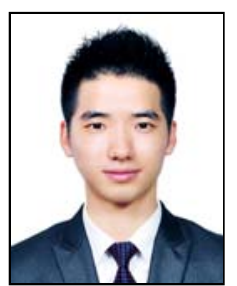

Eunsang Cho was born in Incheon, South Korea. He received the B.S. degree in civil engineering at the Hanyang University, South Korea. He is currently a M.S. candidate in the Department of Civil and Environmental Engineering at the Hanyang University, South Korea. His research interests are the spatio-temporal variability assessment of soil moisture and validation and application using microwave remotely sensed hydrological data.

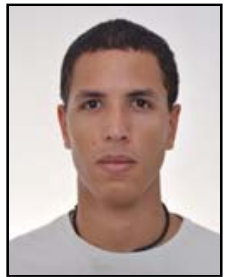

Gabriel Alves Vasconcelos is an undergraduate student in civil engineering of University of Brasilia, Brazil. He was born in Rio de Janeiro, Brazil, in 1990

He was an exchange student, by Science without Borders Program, in Department of Civil and Environmental Engineering at the Hanyang University, South Korea, in 2013.

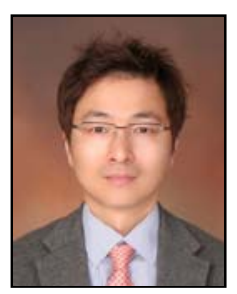

Minha Choi is an associate professor of School of Civil, Architectual, and Environmental Engineering at the Sungkyunkwan University, Suwon, South Korea.

$\mathrm{He}$ received the B.S. and M.S. degree in civil engineering from Korea University, South Korea, and Ph.D. degree in civil engineering from University of New Hampshire, NH, USA, in 2006.

His research interests are natural hydrologic phenomena that frequently cause floods and droughts and significant damage to people and property. A main research goal is to improve knowledge of land surface hydrologic processes and modeling by integrating remotely sensed data and ground-based data with an emphasis on the soil vegetation-atmosphere dynamics over a range of scales. 